\title{
The effects of exhaustive swimming and probiotic administration in trained rats: Oxidative balance of selected organs, colon morphology, and contractility
}

\author{
C Ünsal ${ }^{1}$, H Ünsal ${ }^{1}$, M Ekici ${ }^{1}$, E Koç Yildirim ${ }^{1}$ AG Üner¹, M Yildiz², Ö Güleș ${ }^{3}$, \\ GS Ekren Aşici' ${ }^{4}$, M Boyacioğlu $^{5}$, M Balkaya ${ }^{1}$, F Belge $^{1}$ \\ ${ }^{1}$ Department of Physiology, Faculty of Veterinary Medicine, Adnan Menderes University, Aydin, Turkey \\ ${ }^{2}$ Department of Occupational Health and Safety, Çan School of Applied Sciences, Çanakkale Onsekiz Mart \\ University, Çanakkale, Turkey \\ ${ }^{3}$ Department of Histology and Embryology, Faculty of Veterinary Medicine, Adnan Menderes University, \\ Aydin, Turkey \\ ${ }^{4}$ Department of Biochemistry, Faculty of Veterinary Medicine, Adnan Menderes University, Aydin, Turkey \\ ${ }^{5}$ Department of Pharmacology, Faculty of Veterinary Medicine, Adnan Menderes University, Aydin, Turkey
}

Received: December 18, 2017

Accepted: November 5, 2018

The duration and intensity of exercise are significant factors in oxidative, morphological, and functional changes of the gastrointestinal tract. This study aimed to investigate the effects of both exhaustive swimming and probiotic VSL\#3 on rats that had been previously trained with moderate swimming. The rats were divided into four groups labeled: control (C), probiotic (P), exercise (E), and probiotic-exercise (PE). Groups P and PE were fed with probiotic mixture VSL\#3. Groups $\mathrm{E}$ and PE had a 5-week moderate swimming program ( $1 \mathrm{~h} /$ day for 5 days/week), followed by a 1-week exhaustive swimming program (trained like in moderate program but 3 times with 150 min resting sessions, for 5 days/week). At the end of the program, the rats were euthanized. Malondialdehyde, superoxide dismutase, catalase, and reduced glutathione levels were measured in tissue samples from the gastrocnemius muscle, heart, liver, kidney, and colon. In vitro contractile activity and histomorphology of the colon were also determined. Exercise and/or probiotic decreased the oxidative stress and also increased the level of one or more of the antioxidant enzymes in some of the organs. Probiotics had more pronounced effects on colon morphology than exercise but unexpectedly this effect was non-trophic. In the colon, the thickness of the tunica muscularis and the number of goblet cells were not affected; however, probiotic administration decreased the crypt depth and tunica mucosa thickness. Exercise increased the $\mathrm{E}_{\max }$ value of acetylcholine (ACh), while decreased its sensitivity. These findings suggest that exhaustive swimming does not cause oxidative stress and that probiotic consumption improves oxidative balance in trained rats. The probiotic intake does not alter the effect of exercise on the contractile activity of the colon. Colon mucosal changes induced by probiotics are independent of exercise.

Keywords: oxidative stress, swimming exercise, probiotic, colon morphology, colon contractility

\section{Introduction}

Epidemiological studies show that exercise reduces the incidence of oxidative stress-related diseases. Regular exercise induces the modification of both anti-oxidative and repairing systems, which lowers oxidative damage to the minimum level and increases resistance to oxidative stress (36). According to Radak et al. (35), although organs such as the skeletal

Corresponding author: Cengiz Ünsal, $\mathrm{PhD}$

Department of Physiology, Faculty of Veterinary Medicine, Adnan Menderes University

Işıklı 09016, Aydın, Turkey

Phone: +90 256 2470700; Fax: +90 256 2470720; E-mail: cunsal@adu.edu.tr 
muscle, liver, and brain have different metabolic rates, their adaptive responses to exercise are fairly similar; however, during exercise, the organs may have significantly different oxidative responses (25). The duration and intensity of exercise are the critical factors in the formation of oxidative balance. In general, moderate and prolonged exercise can strengthen the antioxidant defense system (15), whereas during sudden and intense exercise, the oxidative balance shifts to the oxidant status (22). During sudden or intense exercise, the shunting of blood flow from the viscera causes ischemia, accompanied by immune reactions, oxidative damage, and intestinal barrier disruption $(14,20)$. Thus, exhausting exercise may cause some gastrointestinal symptoms, such as bleeding, nausea, cramp, and diarrhea (18).

Probiotics are live microorganisms that have beneficial effects on general health, including gut metabolism. They modulate gastrointestinal microbiota and the immune system, while also providing protection to the intestinal barrier. It is known that probiotics have metabolic, anti-allergic, anti-inflammatory, and anti-oxidative effects (27). Due to their regulative roles in gastrointestinal functions and mucosal immunity, recently, there has been an increase in the probiotic intake of athletes (34). The probiotic intake during prolonged exercise periods may reduce the incidence and/or duration of gastrointestinal symptoms (18) and upper respiratory tract infections (45). Probiotics regulate exercise-induced alterations in pro- and anti-inflammatory cytokines (46) and oxidant-antioxidant status (28). Some strains of lactobacilli and bifidobacteria exert anti-oxidative activity in vivo and in vitro by the scavenging of reactive oxygen species, metal ion chelation, and reductive activity. They also produce antioxidant molecules, such as superoxide dismutase (SOD) and glutathione (GSH) (1).

In addition to the direct anti-oxidative properties of probiotics, they indirectly improve antioxidant activity by inducing several pathways, such as: (1) the inhibition of pathogeninduced inflammation in the intestine, (2) the inhibition of cytokine-induced oxidative damage through stimulation of immune system, (3) the increased antioxidant-absorption from the gastrointestinal tract, and (4) the regulation of lipid metabolism through reduction of lipid-induced oxidative damage $(28,30)$.

There are several studies conducted on the relationships between the different exercise protocols and the oxidative status measured from blood and tissues $(25,35,42)$. The gastrointestinal system is one of the main systems affected by intense exercise and probiotic intake $(34,45)$, but studies on the beneficial effects of probiotic usage on exercise-induced oxidative pathways and mechanisms are limited (34).

Previously, we compared the effects of probiotic VSL\#3 on inflammatory and oxidative parameters in the blood of rats subjected to moderate and exhaustive swimming (44). In this study, we tested the effects of exhaustive swimming and probiotic VSL\#3 on the oxidative balance of different organ tissues, and their effects on the morphometric measurements and contractile activity of the colon.

\section{Materials and Methods}

\section{Animals}

Eight-month-old male Sprague-Dawley rats, weighing 450-600 g, were obtained from Adnan Menderes University Veterinary Faculty Experimental Animal Unit, where the experiment was also performed. Rats were housed in a room at $22 \pm 2{ }^{\circ} \mathrm{C}$ with $55 \%-65 \%$ humidity. The rats were given standard mouse-rat chow (Bil-Yem, Ankara, 
Turkey), consisting of $(2,600 \mathrm{kcal} / \mathrm{kg}$ metabolizable energy, $23 \%$ crude protein, $7 \%$ crude fiber, and $8 \%$ crude ash) and tap water ad libitum. A total of 28 rats were equally divided into four groups: control (C), probiotic $(\mathrm{P})$, exercise $(\mathrm{E})$, and probiotic-exercise (PE). All experimental and animal-care procedures were approved by the Adnan Menderes University Animal Ethics Committee (ADU-HADYEK; approval no.: 64583101/2013/096).

\section{Swimming exercise protocol}

The exercises were performed between 10:00 a.m. and 12:00 p.m. in plastic buckets that possess $90 \mathrm{~cm}$ depth and $50 \mathrm{~cm}$ width, containing $32 \pm 1{ }^{\circ} \mathrm{C}$ water. One week prior to the experiment, the rats were allowed to rest in buckets filled with shallow water for $30 \mathrm{~min}$, to get accustomed to it. During the moderate swimming period $(1 \mathrm{~h} /$ day, 5 days/week for 5 weeks), the rats in groups E and PE swam alone in plastic buckets with a lead load, equivalent to $5 \%$ of their body weight, attached to the tail. Exercise per day consisted of $50 \mathrm{~min}$ of swimming with the load and $10 \mathrm{~min}$ without it. Following a 5-week moderate swimming period, these rats were subjected to exhaustive swimming exercise with load as described in moderate schedule above for 5 days (three times with 150-min resting sessions for $3 \mathrm{~h}$ totally each day). To eliminate the confounding effects of staying in the water, the rats in sedentary groups (groups $\mathrm{C}$ and $\mathrm{P}$ ) were allowed to acclimate to the shallow water without the load, at the same temperature for 30 min once a day during moderate exercise and thrice a day for $30 \mathrm{~min} /$ each trial during exhaustive exercise schedule $(23,41)$.

\section{Probiotic treatment}

Unflavored VSL\#3 sachets (2.5 g) (Sigma-Tau Pharmaceuticals, Inc., Washington, USA), containing corn starch and 450) containing corn starch and 450 billion live freeze-dried bacteria (Streptococcus thermophilus, Bifidobacterium breve, Bifidobacterium longum subsp. Longum and Bifidobacterium longum subsp. infantis, Lactobacillus acidophilus, Lactobacillus plantarum, Lactobacillus paracasei, and Lactobacillus helveticus) were used. An amount of $20 \mathrm{mg}$ probiotic VSL\#3 was dissolved into $75 \mathrm{ml}$ of tap water and provided everyday to groups $\mathrm{P}$ and PE from Monday to Friday for 6 weeks $(9,40)$. The rats approximately consumed $60 \mathrm{ml}$ of water per day and therefore received about $16 \mathrm{mg}$ of probiotic (2.88 billion bacteria).

\section{Determination of body weight, feed, and water consumption}

From the beginning of the experiment, changes in body weight were recorded weekly for a total of seven measurements. Feed and water consumption were recorded daily.

\section{Tissue preparation for analysis}

After the last swimming exercise, the rats were euthanized under ether anesthesia by cervicaldislocation. The liver, left kidney, heart, gastrocnemius muscle, and proximal colon tissues were immediately collected. A 3-cm-long segment of the colon $(0.5 \mathrm{~cm}$ from the ceco-colonic junction) was dissected from each rat and divided into three groups to be used for: (1) an in vitro organ bath experiment, (2) histological analyses, and (3) oxidative analyses, respectively.

In vitro organ bath tests

The luminal contents of the colon segments were cleaned using Krebs-bicarbonate solution [composed of (mmol/L): $128 \mathrm{NaCl}, 4.5 \mathrm{KCl}, 2.5 \mathrm{CaCl}_{2}, 118 \mathrm{MgSO}_{4}, 1.18 \mathrm{KH}_{2} \mathrm{PO}_{4}$, $125 \mathrm{NaHCO}_{3}$, and 5.55 D-Glucose $(\mathrm{pH}$ 7.4)] and the mesenteric tissues surrounding the colon were gently removed. The colonic segments were then mounted vertically under 
$1 \mathrm{~g}$ tension in a $10-\mathrm{ml}$ organ bath, containing continuously oxygenated $\left(5 \% \mathrm{CO}_{2}\right.$ and $\left.95 \% \mathrm{O}_{2}\right)$ Krebs-bicarbonate solution. Colonic segments were allowed to equilibrate for $60 \mathrm{~min}$.

The isometric mechanical activity of the colon segments was recorded with a Biopac MP- $30^{\circledR}$ force transducer (Biopac, Aero Camino, CA, USA). After the equilibration period, the cumulative responses to increasing concentrations of acetylcholine chloride (ACh), ranging from $10^{-8}$ to $10^{-3} \mathrm{~mol} / \mathrm{L}$, were recorded. Outputs were evaluated in the Biopac B.S.L Pro 3.6.7 program (Biopac, Aero Camino, CA, USA). The maximum response to each concentration of $\mathrm{ACh}$ was calculated as the percentage of the maximum contraction response from spontaneous activity. The maximum response to ACh $\left(\mathrm{E}_{\max }\right)$ and the sensitivity $(\mathrm{pD} 2$; $-\log \mathrm{EC}_{50}$ ) were also calculated using GraphPad Prism Version 5.0.2 (GraphPad Software, San Diego, CA, USA).

\section{Oxidative analyses}

The tissues were maintained at $-80{ }^{\circ} \mathrm{C}$ until oxidative analysis could be performed. Before the analysis, tissue samples were cut into small pieces in a petri dish, transferred to a tube, and then homogenized in a $10 \%$ of $150 \mathrm{mM}$ phosphate buffer solution (pH 7.4), using a teflon-head homogenizer (IKA Overhead Stirrer, Germany) at 2,000 rpm for $1 \mathrm{~min}$. Tissue homogenates were then centrifuged (Hettich Zentrifugen, Mikro 200 R, Germany) at $12,000 \mathrm{rpm}$ at $4{ }^{\circ} \mathrm{C}$ for $10 \mathrm{~min}$. After centrifugation, supernatants were collected and analyzed within the same day.

The reaction of malondialdehyde (MDA) with thiobarbituric acid was measured spectrophotometrically (Shimadzu UV-1601, Kyoto, Japan) using a 532-nm filter (32). MDA concentrations were calculated as $\mathrm{nmol} / \mathrm{mg}$ tissue protein by calculating the absorbance coefficient $\left(\varepsilon=1.56 \times 10^{5} / \mathrm{M} / \mathrm{cm}\right)$. The activities of three antioxidant enzymes, such as SOD, catalase (CAT), and GSH, were also determined spectrophotometrically. SOD activity was measured at $560 \mathrm{~nm}$ wave length, according to the method of Sun et al. (43) and the results were obtained as U/mg tissue protein. CAT activity was measured at $240 \mathrm{~nm}$ wave length and the results were calculated as $\mathrm{k} / \mathrm{mg}$ tissue protein (6). The GSH levels were analyzed at $412 \mathrm{~nm}$ wave length and the results were calculated as $\mathrm{mg} / \mathrm{kg}$ tissue protein, compared to standard GSH solution (12). Total protein concentrations were measured spectrophotometrically and the results were calculated as $\mathrm{mg} / \mathrm{ml}$ protein (26).

\section{Histological analyses}

Tissue segments obtained from the proximal colon were washed with $0.9 \% \mathrm{NaCl}$ and fixed in $10 \%$ buffered neutral formalin solution for $24 \mathrm{~h}$. Then, the tissues were routinely embedded in paraffin followed by sectioning.

Transversal sections ( $6 \mu \mathrm{m}$ thickness) with $50 \mu \mathrm{m}$ intervals were taken from the prepared paraffin blocks. Three transversal sections from each rat were subjected to the Crossdom's triple staining method (8) to examine histomorphometric changes, whereas the other three transversal sections were subjected to the periodic acid schiff (PAS) staining method for the demonstration of goblet cells (31).

To determine the histomorphometric changes, a total of 15 sections from the colon of each rat were measured for crypt depth, mucosal thickness (the thicknesses of lamina epithelialis and lamina propria), and tunica muscularis thickness. For each of the three measurements, the five sections were taken from different areas of the colon. In addition, goblet cells were counted within a $100-\mu \mathrm{m}$ area in five crypts of each section stained with the PAS staining method. 


\section{Statistical analysis}

The SPSS 22.0 (IBM Corp. Released 2013, IBM SPSS Statistics for Windows, version 22.0, Armonk, NY, USA) package program was used to evaluate the data. For each variable, the arithmetic mean and the standard error of the mean were determined and the significant value was accepted as $p \leq 0.05$. The Shapiro-Wilk test was used for the evaluation of data distribution. The normally distributed data were analyzed by two-way analysis of variance (ANOVA) to analyze the effects of probiotic and exercise. Repeated measures three-way ANOVA was carried out to analyze the changes in body weight, food and water consumption, and the ACh concentration-response curve. Post hoc analyses were performed by encoding extra code in the syntax menu of the SPSS when the effects of interventions were significant.

\section{Results}

The body weight, food, and water consumption of the rats increased over time throughout the experiment $(p<0.001)$; however, neither probiotics nor exercise were the cause of this increase. At the beginning of the experiment, the average body weight and food- and water-consumption values were $493.61 \mathrm{~g}, 31.32 \mathrm{~g}$, and $58 \mathrm{ml}$, respectively. At the end of the experiment, body weight increased by $7 \%$ to $532.08 \mathrm{~g}$, food consumption increased by $5.46 \%$ to $33.03 \mathrm{~g}$, and the water consumption increased by $8.62 \%$ to $63 \mathrm{ml}$.

\section{Colon smooth muscle contractile activity}

The results obtained from repeated measures three-way ANOVA for the ACh concentrationresponse curves showed that ACh dose, probiotic, probiotic-exercise, and dose-probioticexercise interactions were significant ( $p<0.001, p<0.05, p<0.01, p<0.05$, respectively). The sedentary group fed with probiotic had the maximum contraction response to ACh in all concentrations compared to other groups. The mean differences of the contraction responses were significant between groups $\mathrm{P}$ and $\mathrm{C}$ in $10^{-7}-10^{-3} \mathrm{M}$ ACh concentrations $(p<0.01)$ and significant for groups $\mathrm{P}$ and $\mathrm{PE}$ in $10^{-7}-10^{-5} \mathrm{M}$ ACh concentrations $(p<0.01)$ (Fig. 1). Probiotic-exercise interaction was also significant for the $\mathrm{E}_{\max }(\%)$ value of $\mathrm{ACh}(p<0.05)$. Exercise or probiotic increased the $\mathrm{E}_{\max }(\%)$ value of $\mathrm{ACh}$ compared to the control group (Table I). However, exercise caused the ACh concentration-response curve to deviate toward the right, because the $\mathrm{pD} 2$ values of the exercise groups were lower than those of the sedentary groups (Table I).

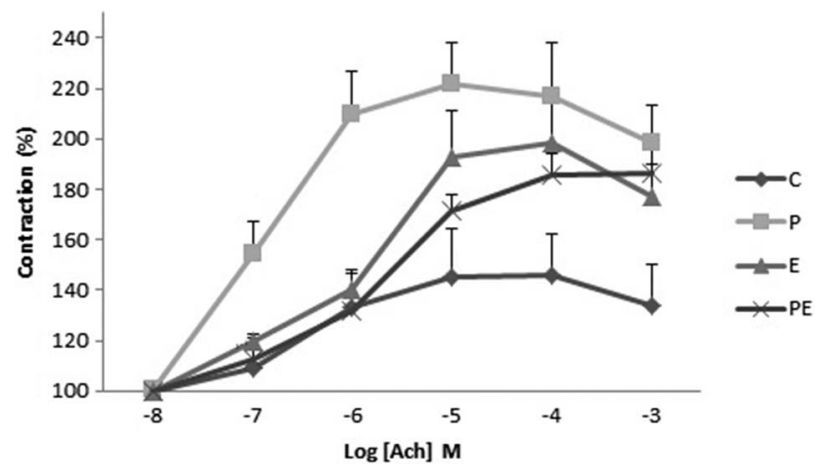

Fig. 1. Cumulative concentration response curve to $\mathrm{ACh}$. The mean differences of the contraction responses were significant between groups $\mathrm{P}$ and $\mathrm{C}$ in $10^{-7}-10^{-3} \mathrm{M} \mathrm{ACh}$ concentrations and significant for groups $\mathrm{P}$ and $\mathrm{PE}$ in $10^{-7}-10^{-5} \mathrm{M} \mathrm{ACh}$ concentrations $(p<0.01)$ 
Table I. ACh response of colon smooth muscle

\begin{tabular}{|c|c|c|}
\hline & $E_{\max }(\%)$ & pD2 $\left(-\operatorname{logEC} C_{50}\right)$ \\
\hline \multicolumn{3}{|l|}{ Probiotic } \\
\hline Probiotic & $209.41 \pm 10.74$ & $6.37 \pm 0.19$ \\
\hline Non-probiotic & $183.95 \pm 14.58$ & $6.30 \pm 0.17$ \\
\hline \multicolumn{3}{|l|}{ Exercise } \\
\hline Exercise & $198.89 \pm 9.22$ & $5.87 \pm 0.09$ \\
\hline Non-exercise & $196.23 \pm 16.90$ & $6.91 \pm 0.13$ \\
\hline \multicolumn{3}{|l|}{ Probiotic $\times$ Exercise } \\
\hline Control & $154.50 \pm 20.75^{\mathrm{a}}$ & $6.67 \pm 0.24^{\mathrm{a}}$ \\
\hline Probiotic & $226.03 \pm 18.36^{\mathrm{b}}$ & $7.05 \pm 0.08^{\mathrm{a}}$ \\
\hline Exercise & $204.99 \pm 16.90^{\mathrm{b}}$ & $6.06 \pm 0.11^{\mathrm{b}}$ \\
\hline Probiotic-exercise & $192.78 \pm 9.92^{\mathrm{a}, \mathrm{b}}$ & $5.70 \pm 0.09^{\mathrm{b}}$ \\
\hline \multicolumn{3}{|l|}{$p$ value } \\
\hline Probiotic & NS & NS \\
\hline Exercise & NS & $<0.001$ \\
\hline Interaction & $<0.05$ & $<0.05$ \\
\hline
\end{tabular}

Data were represented as mean \pm standard error of mean. Means marked with different superscripts (a and b) significantly differ from each other in the same column. NS: not significant; Ach: acetylcholine

Table II. Effects of probiotic administration and exercise on oxidant-antioxidant status of selected tissues

\begin{tabular}{|c|c|c|c|c|}
\hline & $\begin{array}{c}\text { MDA }(\mathbf{n m o l} / \mathbf{m g} \\
\text { protein) }\end{array}$ & $\begin{array}{c}\text { GSH } \\
\text { (mg/g protein) }\end{array}$ & $\begin{array}{c}\text { SOD } \\
\text { (U/mg protein) }\end{array}$ & $\begin{array}{c}\text { CAT } \\
(\mathrm{K} / \mathrm{mg})\end{array}$ \\
\hline \multicolumn{5}{|l|}{ Colon } \\
\hline \multicolumn{5}{|l|}{ Probiotic } \\
\hline Probiotic & $9.00 \pm 0.56$ & $5.06 \pm 0.71$ & $3.41 \pm 0.04$ & $1.74 \pm 0.26$ \\
\hline Non-probiotic & $9.34 \pm 0.43$ & $4.40 \pm 0.45$ & $3.24 \pm 0.04$ & $0.82 \pm 0.20$ \\
\hline \multicolumn{5}{|l|}{ Exercise } \\
\hline Exercise & $9.20 \pm 0.50$ & $4,50 \pm 0.41$ & $3,34 \pm 0.04$ & $1,39 \pm 0.32$ \\
\hline Non-Exercise & $9.14 \pm 0.50$ & $4.96 \pm 0.74$ & $3.31 \pm 0.06$ & $1.18 \pm 0.20$ \\
\hline \multicolumn{5}{|c|}{ Probiotic $\times$ Exercise } \\
\hline Control & $8.76 \pm 0.50$ & $3.83 \pm 0.49$ & $3.17 \pm 0.07$ & $1.15 \pm 0.30^{\mathrm{a}}$ \\
\hline Probiotic & $9.51 \pm 0.93$ & $6.08 \pm 1.31$ & $3.45 \pm 0.06$ & $1.20 \pm 0.27^{\mathrm{a}}$ \\
\hline Exercise & $9.92 \pm 0.72$ & $4.95 \pm 0.72$ & $3.30 \pm 0.04$ & $0.49 \pm 0.22^{\mathrm{a}}$ \\
\hline
\end{tabular}


Table II. Effects of probiotic administration and exercise on oxidant-antioxidant status of selected tissues (Continued)

\begin{tabular}{|c|c|c|c|c|}
\hline & $\begin{array}{c}\text { MDA (nmol/mg } \\
\text { protein) }\end{array}$ & $\begin{array}{c}\text { GSH } \\
\text { (mg/g protein) }\end{array}$ & $\begin{array}{c}\text { SOD } \\
\text { (U/mg protein) }\end{array}$ & $\begin{array}{c}\text { CAT } \\
(\mathrm{K} / \mathrm{mg})\end{array}$ \\
\hline Probiotic-exercise & $8.49 \pm 0.93$ & $4.04 \pm 0.44$ & $3.38 \pm 0.09$ & $2.28 \pm 0.41^{\mathrm{b}}$ \\
\hline \multicolumn{5}{|l|}{$p$ value } \\
\hline Probiotic & NS & NS & $<0.01$ & $<0.01$ \\
\hline Exercise & NS & NS & NS & NS \\
\hline Interaction & NS & NS & NS & $<0.01$ \\
\hline \multicolumn{5}{|l|}{ Liver } \\
\hline \multicolumn{5}{|l|}{ Probiotic } \\
\hline Probiotic & $1.16 \pm 0.08$ & $2.30 \pm 0.11$ & $0.36 \pm 0.02$ & $4.75 \pm 0.52$ \\
\hline Non-probiotic & $1.15 \pm 0.07$ & $2.01 \pm 0.12$ & $0.31 \pm 0.01$ & $5.65 \pm 0.80$ \\
\hline \multicolumn{5}{|l|}{ Exercise } \\
\hline Exercise & $1.10 \pm 0.08$ & $2.19 \pm 0.14$ & $0.33 \pm 0.01$ & $3.58 \pm 0.23$ \\
\hline Non-exercise & $1.21 \pm 0.07$ & $2.11 \pm 0.11$ & $0.35 \pm 0.02$ & $6.73 \pm 0.69$ \\
\hline \multicolumn{5}{|l|}{ Probiotic $\times$ Exercise } \\
\hline Control & $1.06 \pm 0.09^{\mathrm{a}, \mathrm{b}}$ & $1.83 \pm 0.07$ & $0.30 \pm 0.01^{\mathrm{a}}$ & $7.66 \pm 1.15$ \\
\hline Probiotic & $1.35 \pm 0.09^{\mathrm{c}}$ & $2.40 \pm 0.13$ & $0.39 \pm 0.02^{\mathrm{b}}$ & $5.80 \pm 0.70$ \\
\hline Exercise & $1.23 \pm 0.11^{\mathrm{b}, \mathrm{c}}$ & $2.18 \pm 0.22$ & $0.32 \pm 0.02^{\mathrm{a}}$ & $3.63 \pm 0.32$ \\
\hline Probiotic-exercise & $0.93 \pm 0.07^{\mathrm{a}}$ & $2.20 \pm 0.18$ & $0.34 \pm 0.02^{\mathrm{a}}$ & $3.52 \pm 0.38$ \\
\hline \multicolumn{5}{|l|}{$p$ value } \\
\hline Probiotic & NS & NS & 0.004 & NS \\
\hline Exercise & NS & NS & NS & $<0.001$ \\
\hline Interaction & 0.004 & NS & 0.036 & NS \\
\hline \multicolumn{5}{|l|}{ Kidney } \\
\hline \multicolumn{5}{|l|}{ Probiotic } \\
\hline Probiotic & $0.96 \pm 0.06$ & $2.22 \pm 0.20$ & $0.10 \pm 0.01$ & $3.61 \pm 0.36$ \\
\hline Non-probiotic & $1.17 \pm 0.06$ & $2.75 \pm 0.16$ & $0.10 \pm 0.01$ & $4.21 \pm 0.44$ \\
\hline \multicolumn{5}{|l|}{ Exercise } \\
\hline Exercise & $1.03 \pm 0.08$ & $2.34 \pm 0.25$ & $0.10 \pm 0.01$ & $3.92 \pm 0.54$ \\
\hline Non-exercise & $1.10 \pm 0.06$ & $2.64 \pm 0.11$ & $0.10 \pm 0.01$ & $3.91 \pm 0.27$ \\
\hline \multicolumn{5}{|l|}{ Probiotic $\times$ Exercise } \\
\hline Control & $1.15 \pm 0.10$ & $2.57 \pm 0.17^{\mathrm{b}}$ & $0.09 \pm 0.01$ & $3.53 \pm 0.36^{\mathrm{a}, \mathrm{b}}$ \\
\hline
\end{tabular}


Table II. Effects of probiotic administration and exercise on oxidant-antioxidant status of selected tissues (Continued)

\begin{tabular}{|c|c|c|c|c|}
\hline & $\begin{array}{c}\text { MDA }(\mathbf{n m o l} / \mathbf{m g} \\
\text { protein) }\end{array}$ & $\begin{array}{c}\text { GSH } \\
\text { (mg/g protein) }\end{array}$ & $\begin{array}{c}\text { SOD } \\
\text { (U/mg protein) }\end{array}$ & $\begin{array}{c}\text { CAT } \\
(\mathrm{K} / \mathrm{mg})\end{array}$ \\
\hline Probiotic & $1.06 \pm 0.06$ & $2.71 \pm 0.15^{\mathrm{b}}$ & $0.10 \pm 0.01$ & $4.29 \pm 0.36^{\mathrm{a}, \mathrm{b}}$ \\
\hline Exercise & $1.19 \pm 0.09$ & $2.93 \pm 0.26^{\mathrm{b}}$ & $0.11 \pm 0.01$ & $4.88 \pm 0.75^{\mathrm{a}}$ \\
\hline Probiotic-exercise & $0.84 \pm 0.09$ & $1.65 \pm 0.25^{\mathrm{a}}$ & $0.09 \pm 0.01$ & $2.81 \pm 0.52^{\mathrm{b}}$ \\
\hline \multicolumn{5}{|l|}{$p$ value } \\
\hline Probiotic & $<0.05$ & $<0.05$ & NS & NS \\
\hline Exercise & NS & NS & NS & NS \\
\hline Interaction & NS & $<0.01$ & NS & $<0.05$ \\
\hline \multicolumn{5}{|l|}{ Gastrocnemius muscle } \\
\hline \multicolumn{5}{|l|}{ Probiotic } \\
\hline Probiotic & $6.89 \pm 0.34$ & $3.35 \pm 0.20$ & $3.21 \pm 0.06$ & $0.59 \pm 0.08$ \\
\hline Non-probiotic & $6.44 \pm 0.20$ & $2.84 \pm 0.27$ & $3.15 \pm 0.04$ & $1.14 \pm 0.21$ \\
\hline \multicolumn{5}{|l|}{ Exercise } \\
\hline Exercise & $6.16 \pm 0.12$ & $3.04 \pm 0.16$ & $3.26 \pm 0.05$ & $0.91 \pm 0.20$ \\
\hline Non-exercise & $7.17 \pm 0.33$ & $3.15 \pm 0.29$ & $3.10 \pm 0.05$ & $0.82 \pm 0.15$ \\
\hline \multicolumn{5}{|l|}{ Probiotic $\times$ Exercise } \\
\hline Control & $6.87 \pm 0.30$ & $2.88 \pm 0.43$ & $3.12 \pm 0.05$ & $1.04 \pm 0.23$ \\
\hline Probiotic & $7.47 \pm 0.60$ & $3.41 \pm 0.41$ & $3.08 \pm 0.08$ & $0.60 \pm 0.15$ \\
\hline Exercise & $6.00 \pm 0.17$ & $2.81 \pm 0.36$ & $3.18 \pm 0.07$ & $1.25 \pm 0.35$ \\
\hline Probiotic-exercise & $6.31 \pm 0.20$ & $3.28 \pm 0.02$ & $3.34 \pm 0.05$ & $0.57 \pm 0.09$ \\
\hline \multicolumn{5}{|l|}{$p$ value } \\
\hline Probiotic & NS & NS & NS & $<0.05$ \\
\hline Exercise & $<0.01$ & NS & $<0.05$ & NS \\
\hline Interaction & NS & NS & NS & NS \\
\hline \multicolumn{5}{|l|}{ Heart } \\
\hline \multicolumn{5}{|l|}{ Probiotic } \\
\hline Probiotic & $2.28 \pm 0.08$ & $4.91 \pm 0.31$ & $0.38 \pm 0.01$ & $0.36 \pm 0.01$ \\
\hline Non-probiotic & $2.25 \pm 0.09$ & $4.75 \pm 0.34$ & $0.34 \pm 0.01$ & $0.34 \pm 0.01$ \\
\hline \multicolumn{5}{|l|}{ Exercise } \\
\hline Exercise & $2.10 \pm 0.07$ & $4.62 \pm 0.29$ & $0.37 \pm 0.01$ & $0.35 \pm 0.01$ \\
\hline Non-exercise & $2.41 \pm 0.07$ & $5.02 \pm 0.35$ & $0.35 \pm 0.01$ & $0.35 \pm 0.01$ \\
\hline
\end{tabular}


Table II. Effects of probiotic administration and exercise on oxidant-antioxidant status of selected tissues (Continued)

\begin{tabular}{|c|c|c|c|c|}
\hline & $\begin{array}{c}\text { MDA }(\mathbf{n m o l} / \mathbf{m g} \\
\text { protein) }\end{array}$ & $\begin{array}{c}\text { GSH } \\
\text { (mg/g protein) }\end{array}$ & $\begin{array}{c}\text { SOD } \\
\text { (U/mg protein) }\end{array}$ & $\begin{array}{c}\text { CAT } \\
(\mathrm{K} / \mathbf{m g})\end{array}$ \\
\hline \multicolumn{5}{|l|}{ Probiotic $\times$ Exercise } \\
\hline Control & $2.46 \pm 0.11$ & $5.59 \pm 0.46^{\mathrm{b}}$ & $0.33 \pm 0.01$ & $0.37 \pm 0.02^{\mathrm{a}, \mathrm{c}}$ \\
\hline Probiotic & $2.37 \pm 0.10$ & $4.45 \pm 0.47^{\mathrm{a}, \mathrm{c}}$ & $0.36 \pm 0.01$ & $0.33 \pm 0.02^{\mathrm{b}, \mathrm{c}}$ \\
\hline Exercise & $2.03 \pm 0.07$ & $3.91 \pm 0.26^{\mathrm{a}}$ & $0.35 \pm 0.01$ & $0.32 \pm 0.01^{\mathrm{b}}$ \\
\hline Probiotic-exercise & $2.18 \pm 0.14$ & $5.46 \pm 0.31^{\mathrm{b}, \mathrm{c}}$ & $0.40 \pm 0.01$ & $0.39 \pm 0.02^{\mathrm{a}}$ \\
\hline \multicolumn{5}{|l|}{$p$ value } \\
\hline Probiotic & NS & NS & $<0.001$ & NS \\
\hline Exercise & $<0.01$ & NS & $<0.05$ & NS \\
\hline Interaction & NS & $<0.01$ & NS & $<0.01$ \\
\hline
\end{tabular}

Data are shown as mean \pm standard error of mean. Means marked with different superscripts ( $a, b$, and c) significantly differ from each other in the same column. NS: not significant; MDA: malondialdehyde; GSH: glutathione; SOD: superoxide dismutase; CAT: catalase

Table III. Effects of probiotic administration and/or exercise on histomorphological features of colon

\begin{tabular}{|c|c|c|c|c|}
\hline & Crypt depth & $\begin{array}{l}T . \text { mucosa } \\
\text { thickness }\end{array}$ & $\begin{array}{l}\text { T. muscularis } \\
\text { thickness }\end{array}$ & $\begin{array}{c}\text { Goblet cell } \\
\text { number }\end{array}$ \\
\hline \multicolumn{5}{|l|}{ Probiotic } \\
\hline Probiotic & $189.10 \pm 4.29$ & $244.44 \pm 5.76$ & $193.60 \pm 9.04$ & $14.44 \pm 0.33$ \\
\hline Non-probiotic & $218.56 \pm 6.69$ & $285.45 \pm 5.42$ & $189.68 \pm 7.89$ & $14.16 \pm 0.34$ \\
\hline \multicolumn{5}{|l|}{ Exercise } \\
\hline Exercise & $202.86 \pm 7.41$ & $260.08 \pm 9.77$ & $188.91 \pm 8.97$ & $14.00 \pm 0.31$ \\
\hline Non-exercise & $204.70 \pm 6.46$ & $269.81 \pm 5.30$ & $194.37 \pm 7.93$ & $14.60 \pm 0.34$ \\
\hline \multicolumn{5}{|l|}{ Probiotic $\times$ Exercise } \\
\hline Control & $225.93 \pm 5.19$ & $287.32 \pm 3.95$ & $198.77 \pm 11.13$ & $14.80 \pm 0.46$ \\
\hline Probiotic & $183.47 \pm 3.37$ & $252.30 \pm 2.89$ & $189.97 \pm 13.32$ & $14.40 \pm 0.58$ \\
\hline Exercise & $211.20 \pm 12.51$ & $283.58 \pm 10.72$ & $180.58 \pm 12.39$ & $13.53 \pm 0.45$ \\
\hline Probiotic-exercise & $194.52 \pm 9.02$ & $236.58 \pm 12.68$ & $197.24 \pm 15.51$ & $14.47 \pm 0.45$ \\
\hline \multicolumn{5}{|l|}{$p$ value } \\
\hline Probiotic & $<0.01$ & $<0.001$ & NS & NS \\
\hline Exercise & NS & NS & NS & NS \\
\hline Interaction & NS & NS & NS & NS \\
\hline
\end{tabular}

Data are shown as mean \pm standard error of mean. NS: not significant 


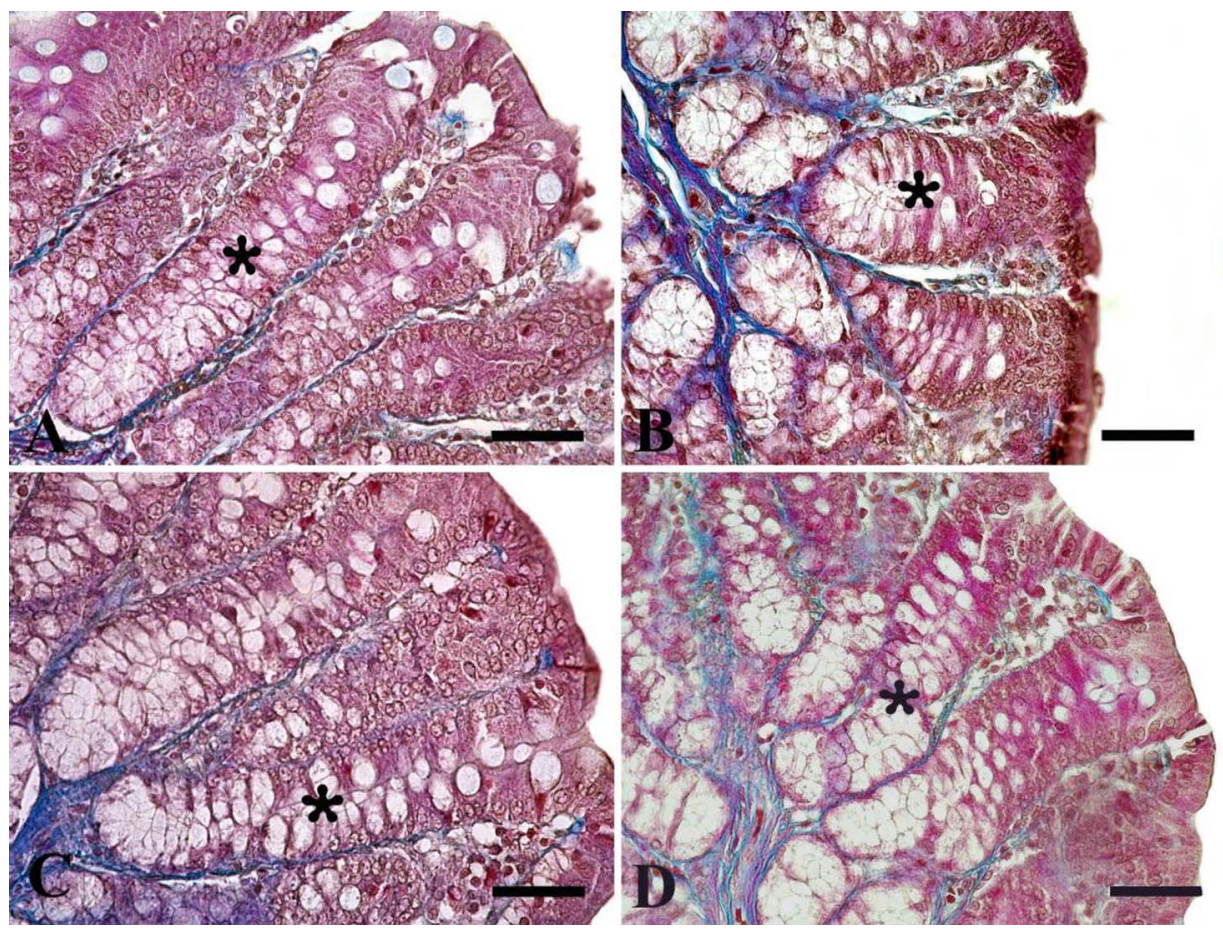

Fig. 2. Microscopic imaging of crypt depths in colon. It is seen that the crypt depth $(*)$ decreased in groups given probiotic $(p<0.01)$; Group P (B) and Group PE (D). Triple staining method. Bars: $50 \mu \mathrm{m}$

\section{Oxidative parameters}

The results are shown in Table II. Exhaustive exercise in the trained rats did not induce oxidative stress in the examined organs. Moreover, exercise decreased the MDA level in gastrocnemius muscle and heart $(p<0.01)$. Probiotic decreased the MDA level in the kidney, whereas probiotic intake together with exercise decreased the MDA in the liver $(p<0.05$ and $p<0.01$, respectively).

Responses of antioxidant molecules to exercise and/or probiotic were different and dependent on the type of antioxidant molecules or organs. Probiotic increased the SOD and CAT levels in the colon $(p<0.01)$. Furthermore, mean CAT level was higher in the PE group than in the other groups $(p<0.01)$. Probiotic also increased the SOD level in the liver $(p<0.01)$ but probiotic intake together with exercise decreased it $(p<0.05)$. On the other hand, CAT level of the liver decreased in the exercised groups $(p<0.001)$. Probiotic led to significant reductions in GSH levels of the kidney $(p<0.05)$. GSH levels in the kidneys of the exercised rats fed with probiotic decreased compared to the other groups $(p<0.01)$. Otherwise, exhaustive exercise also decreased the GSH level in the heart but probiotic consumption restored this effect.

Exercise and probiotic administration, or both, led to significant changes in SOD levels of all selected organs except for the kidney. SOD level is the lowest in the kidney among the organs. Probiotic increased the SOD levels in the colon $(p<0.05)$, but probiotic-exercise interaction had no effect on colon SOD levels. Probiotic also increased the SOD levels in the liver $(p<0.01)$, whereas exercise decreased it. Liver SOD levels of the sedentary group, fed 


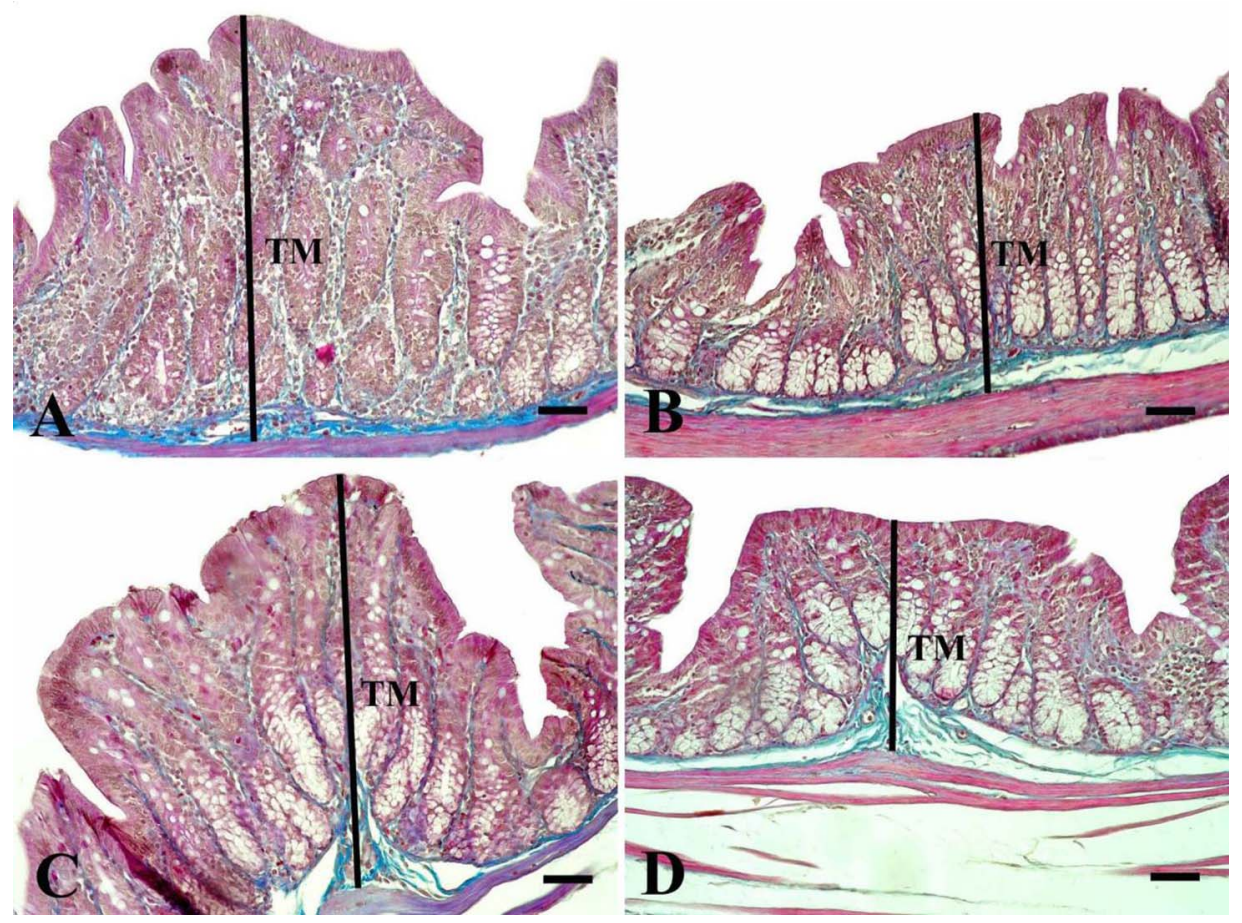

Fig. 3. Microscopic imaging of tunica mucosa thicknesses in the colon. It is seen that the tunica mucosa thickness (black lines) decreased in groups given probiotic $(p<0.001)$; Group P (B) and Group PE (D). TM: tunica mucosa. Triple staining method. Bars: $50 \mu \mathrm{m}$

with probiotic, were higher than those of other groups $(p<0.05)$. Probiotic or exercise increased the SOD levels in the heart $(p<0.01$ and $p<0.05$, respectively), but their interaction was not significant. Exercise also increased the SOD level in the gastrocnemius muscle $(p<0.05)$.

Probiotic and probiotic intake during exercise increased the CAT levels of the colon and the heart $(p<0.01)$. However, exercise decreased liver CAT levels $(p<0.01)$.

\section{Histomorphological measurements}

Probiotic intake and/or swimming exercise did not affect tunica muscularis thickness and goblet cell number (Table III). Probiotic intake decreased the crypt depth $(p<0.01)$ and tunica mucosa thickness $(p<0.001)$ in both the sedentary and the exercised group (Figs 2 and 3), respectively. However, pathological changes such as cell damage or tissue degeneration were not observed in the colon mucosa.

\section{Discussion}

The main goal of using probiotics in sports is to maintain general well-being by improving gut health and mucosal immunity (34). Improving of intestinal microbiota and mucosal immunity modifies the oxidant-antioxidant balance positively by inhibiting immunemediated oxidative damage $(28,30)$. In this study, the oxidative/antioxidant status of some 
organs was evaluated after 5 days of exhaustive swimming exercise in rats that had consumed probiotic VSL\#3 and were trained with moderate swimming for 5 weeks.

We previously demonstrated that plasma protein carbonyl levels do not change and MDA levels decreased in rats exercised with moderate and exhaustive swimming (44). The results gathered in this study demonstrate that exhaustive swimming exercise does not induce oxidative stress in the selected organs of trained rats. Moreover, it reduces lipid peroxidation in the gastrocnemius muscle and in the heart $(p<0.01)$. Although acute exhaustive or chronic exercise increases oxidative stress (25), our findings support the idea that the chronic exercise has beneficial effects in improving metabolic adaptation and maintaining oxidant balance $(37,42,44)$. The serum lactate levels were not examined in this study. The swimming program applied was defined as moderate and exhaustive according to Santos et al. (41). Because the exhausting swimming exercise does not cause oxidative stress, this protocol might not be considered as sufficiently exhausting. However, the moderate training protocol applied in this study (5\% overload, $60 \mathrm{~min} /$ day-5 days/week) is considered as highly intensive according to Ravi Kiran et al. (37). We also found that probiotic intake during exercise led to a reduction in lipid peroxidation of the liver, whereas it led to an increase in antioxidant enzymes such as SOD and/or CAT in the colon and in the heart. In the kidney, probiotic intake decreased the MDA level, but probiotic-exercise interaction was not significant. There is limited information in the literature suggesting that probiotic supplementation reduces the oxidative stress by increasing plasma antioxidant levels and neutralizing reactive oxygen species (28). However, probiotic supplementation may not affect plasma total oxidant status and MDA levels even though there is a tendency for athletes to have decreased protein oxidation (21). During the exercise, increased catecholamine levels and the use of free fatty acids as energy sources enhance the production of mitochondrial and peroxisomal ROS especially in the muscle tissue (17). The results of this study show that skeletal and heart muscles are adapted to exercise during moderate swimming training. Exercise reduced lipid peroxidation and increased SOD levels in both of the muscle tissues. It is noteworthy that the use of probiotics in exercise increases antioxidant activity in the heart muscle. Our findings support previous observations demonstrating that various strains of Lactobacillus and Bifidobacterium have a strong antioxidant effect (1). Antioxidant consumption for the neutralization of reactive oxygen species leads to a reduction in antioxidant molecules (28) and this evidence may explain the reduction in liver SOD and CAT enzymes of both exercised groups and the reduction in GSH in the kidneys of group PE compared to the other groups. Oxygen consumption, antioxidant levels, other scavenging systems and susceptibility to oxidants, and antioxidant enzyme activity of organs may affect the degree of oxidative/anti-oxidative response of organs to exercise (25).

The gastrointestinal tract is one of the primary systems affected by exercise-induced stress. Ischemia-reperfusion events during aerobic training induce some changes in the intestinal morphology, contractile activity, and oxidative variables. These changes are associated with the type, severity, and duration of exercise $(2,3,11,38)$. In mice, intensive treadmill exercise for 4 days causes mucosal degenerations and a prominent (37\%) reduction of the muscular layer of the ileum as well as reduced efficacy against contractile agents (carbachol and $\mathrm{KCl}$ ). Four-day exercise also leads to a reduction in lipid peroxidation with no alteration of protein oxidation (38). However, in mice, intensive treadmill exercise for 10 days does not lead to mucosal degeneration and contractile activity changes and causes only $11 \%$ of muscular layer atrophy with an increase in protein-oxidation levels (38). Moderate aerobic treadmill exercise increases the $\mathrm{E}_{\max }$ of the ACh response in the ileum of 
mice trained for 10, 25, and 40 days, whereas it decreases $\mathrm{E}_{\max }$ in mice trained for 55 days. Furthermore, lipid peroxidation is reduced and the morphological characteristics of the ileum are not changed (11). On the other hand, carbamylcholine hydrochloride $(\mathrm{CCh})$ response curves are attenuated ( $\mathrm{E}_{\max }$ values were lower) in rats subjected to swimming exercise for 2,4 , and 6 weeks, but potency of CCh increased in rats subjected to swimming exercise for 8 weeks. Only 4-week swimming exercise reduces the circular muscle layer, but increases longitudinal muscle layer and lipid peroxidation of the ileum (3). Similarly, acute aerobic exercise reduces both efficacy and relative potency of carbachol in the ileum of rats, but lipid peroxidation and the muscular layer of ileum does not change (2). This study also indicates that exercise reduced the ACh efficacy or sensitivity, because the $\mathrm{pD} 2$ value of ACh was lower in exercise groups compared to sedentary groups $(p<0.001)$. Exercise-induced reduction in the sensitivity of ACh was not restored by probiotic VSL\#3. Moreover, the mean $\mathrm{pD} 2$ value of PE group was lower than that observed in the E group. $\mathrm{E}_{\max }$ values of $\mathrm{ACh}$ in both groups $\mathrm{P}$ and $\mathrm{E}$ were higher than the $\mathrm{E}_{\max }$ value in group $\mathrm{C}$. Although probiotic VSL\#3 increased the ACh dose-response curve in sedentary rats, similar responses were not observed in exercised rats. The results obtained from both the in vivo and in vitro studies indicate that the effects of probiotics on intestinal motility are both stimulatory $(5,19)$ and/or inhibitory (10), since they are regulatory preparations. There was no correlation between the oxidative parameters and the contractile activity of colon.

Consistent with some of the previous studies $(2,11)$, exercise did not change tunica muscularis thickness. However, probiotic intake led to a reduction in tunica mucosa thickness and crypt depth in both sedentary and exercised rats fed with probiotic. The evaluation of intestinal morphology gives insight into the intestinal absorption surface and cell cycle. An increase in these measurements affects performance positively by enhancing the digestive and absorptive activities. Thus, probiotics are used as performance enhancers, especially in broiler-breeding (29). However, there is also some evidence supporting our findings. Probiotics reduce proliferation rates in hyperproliferative and neoplastic conditions $(16,39)$ as well as in normal healthy colon mucosa $(24)$. In addition, the effects of probiotic vary depending on the intestinal segment (4) as well as the type, dose, and exposure time (47). Probiotic delivery routes, such as food, water, and oral gavage, do not affect bacterial viability $(7,13)$ and do not cause significant changes in intestinal morphology in broilers $(33)$. It has been reported that the depth of the crypt is directly proportional to the tissueregeneration rate and the inflammatory process increases this regeneration rate (48). In this study, reductions in crypt depth and tunica mucosa thickness in both sedentary and exercised groups fed with probiotic may be due to the probiotic-induced reduction of enteropathogens and inflammatory and oxidative damage. Although this study does not provide any evidence regarding the microbiota and mucosal immunity, the increase in SOD and CAT levels of the rats that consumed probiotics supports the notion that the oxidative balance shifts toward the antioxidant direction in the colon.

In summary, exhaustive swimming exercise in trained rats does not produce oxidative stress. On the contrary, it causes a decrease in oxidative stress in some organs including gastrocnemius and heart muscle. Probiotic consumption during exercise improves the oxidative balance. On the other hand, probiotic intake leads to a reduction in mucosal measurements of the colon, whereas exercise has no effect on its morphological characteristics. Exercise increases the $\mathrm{E}_{\max }$ value of $\mathrm{ACh}$ but decreases its sensitivity. However, probiotic intake does not alter the effect of exercise on the contractile activity of the colon. 
In summary, probiotic consumption during exercise can be recommended, because it has beneficial effects on the oxidative balance of some organs. However, the determination of the role of probiotics in the adaptation of the intestines to the exercise in different exercise models will provide significant contributions to both gastrointestinal health and general well-being.

\section{Acknowledgements}

This study was funded by the Adnan Menderes University Research Fund (project number: VTF14017). Another part of this study was published in Kafkas Univ Vet Fak 2017; 23: 101 and published as meeting abstract (PC049) in Acta Physiologica (2016; 218: 44-44). The authors would like to thank Amanda Chilaka for her kind help in careful proofreading of this manuscript.

\section{Conflict of interest}

All authors declare no conflict of interest.

\section{REFERENCES}

1. Amaretti A, di Nunzio M, Pompei A, Raimondi S, Rossi M, Bordoni A: Antioxidant properties of potentially probiotic bacteria: in vitro and in vivo activities. Appl. Microbiol. Biotechnol. 97, 809-817 (2013)

2. Araujo LC, de Souza IL, Vasconcelos LH, Brito Ade F, Queiroga FR, Silva AS, da Silva PM, Cavalcante Fde A, da Silva BA: Acute aerobic swimming exercise induces distinct effects in the contractile reactivity of rat ileum to $\mathrm{KCl}$ and carbachol. Front. Physiol. 7, 103 (2016)

3. Araujo LC, de Souza IL, Vasconcelos LH, Brito Ade F, Queiroga FR, Silva AS, da Silva PM, Cavalcante Fde A, da Silva BA: Chronic aerobic swimming exercise promotes functional and morphological changes in rat ileum. Biosci. Rep. 35, e00259 (2015)

4. Awad WA, Ghareeb K, Abdel-Raheem S, Bohm J: Effects of dietary inclusion of probiotic and synbiotic on growth performance, organ weights, and intestinal histomorphology of broiler chickens. Poult. Sci. 88, 49-56 (2009)

5. Bar F, Von Koschitzky H, Roblick U, Bruch HP, Schulze L, Sonnenborn U, Bottner M, Wedel T: Cell-free supernatants of Escherichia coli Nissle 1917 modulate human colonic motility: evidence from an in vitro organ bath study. Neurogastroenterol. Motil. 21, 559-566, e16-17 (2009)

6. Bergmeyer HU, Gawehn K, Grassl M (1974): Glucose-6-phosphate dehydrogenase. In: Methods of Enzymatic Analysis, ed Bergmeyer HU, Academic Press, New York, pp. 458-459

7. Corcoran BM, Ross RP, Fitzgerald GF, Stanton C: Comparative survival of probiotic lactobacilli spray-dried in the presence of prebiotic substances. J. Appl. Microbiol. 96, 1024-1039 (2004)

8. Culling CFA, Allison RT, Barr WT (1985): Cellular Pathology Technique. Butterworth-Heinemann, London

9. Dai C, Zhao DH, Jiang M: VSL\#3 probiotics regulate the intestinal epithelial barrier in vivo and in vitro via the p38 and ERK signaling pathways. Int. J. Mol. Med. 29, 202-208 (2012)

10. Dalziel JE, Mohan V, Peters J, Anderson RC, Gopal PK, Roy NC: The probiotic Escherichia coli Nissle 1917 inhibits propagating colonic contractions in the rat isolated large intestine. Food Funct. 6, 257-264 (2015)

11. de Lira CA, Vancini RL, Ihara SS, da Silva AC, Aboulafia J, Nouailhetas VL: Aerobic exercise affects C57BL/6 murine intestinal contractile function. Eur. J. Appl. Physiol. 103, 215-223 (2008)

12. Fairbanks VF, Klee GG (1987): Biochemical aspects of hematology. In: Fundamentals of Clinical Chemistry, ed Tietz NW, W.B. Saunders Company, Philadelphia, pp. 794-795

13. Gardiner GE, O'sullivan E, Kelly J, Auty MA, Fitzgerald GF, Collins JK, Ross RP, Stanton C: Comparative survival rates of human-derived probiotic Lactobacillus paracasei and L. salivarius strains during heat treatment and spray drying. Appl. Environ. Microbiol. 66, 2605-2612 (2000)

14. Gloire G, Legrand-Poels S, Piette J: NF- $\kappa B$ activation by reactive oxygen species: fifteen years later. Biochem. Pharmacol. 72, 1493-1505 (2006)

15. Gomez-Cabrera MC, Domenech E, Vina J: Moderate exercise is an antioxidant: upregulation of antioxidant genes by training. Free Radic. Biol. Med. 44, 126-131 (2008) 
16. Grimoud J, Durand H, de Souza S, Monsan P, Ouarne F, Theodorou V, Roques C: In vitro screening of probiotics and synbiotics according to anti-inflammatory and anti-proliferative effects. Int. J. Food Microbiol. 144, 42-50 (2010)

17. Ji LL, Leichtweis S: Exercise and oxidative stress: sources of free radicals and their impact on antioxidant systems. Age (Ohama) 20, 91-106 (1997)

18. Kekkonen RA, Vasankari TJ, Vuorimaa T, Haahtela T, Julkunen I, Korpela R: The effect of probiotics on respiratory infections and gastrointestinal symptoms during training in marathon runners. Int. J. Sport Nutr. Exerc. Metab. 17, 352-363 (2007)

19. Kim SE, Choi SC, Park KS, Park MI, Shin JE, Lee TH, Jung KW, Koo HS, Myung SJ, Constipation Research group of Korean Society of Neurogastroenterology and Motility: Change of fecal flora and effectiveness of the short-term VSL\#3 probiotic treatment in patients with functional constipation. J. Neurogastroenterol. Motil. 21, 111-120 (2015)

20. Lambert GP: Stress-induced gastrointestinal barrier dysfunction and its inflammatory effects. J. Anim. Sci. 87, E101-108 (2009)

21. Lamprecht M, Bogner S, Schippinger G, Steinbauer K, Fankhauser F, Hallstroem S, Schuetz B, Greilberger JF: Probiotic supplementation affects markers of intestinal barrier, oxidation, and inflammation in trained men; a randomized, double-blinded, placebo-controlled trial. J. Int. Soc. Sports Nutr. 9, 45 (2012)

22. Leeuwenburgh C, Heinecke JW: Oxidative stress and antioxidants in exercise. Curr. Med. Chem. 8, 829-838 (2001)

23. Lima FD, Stamm DN, Della-Pace ID, Dobrachinski F, de Carvalho NR, Royes LF, Soares FA, Rocha JB, Gonzalez-Gallego J, Bresciani G: Swimming training induces liver mitochondrial adaptations to oxidative stress in rats submitted to repeated exhaustive swimming bouts. PLoS One 8, e55668 (2013)

24. Linsalata M, Russo F, Berloco P, Valentini AM, Caruso ML, De Simone C, Barone M, Polimeno L, Di Leo A: Effects of probiotic bacteria (VSL\#3) on the polyamine biosynthesis and cell proliferation of normal colonic mucosa of rats. In Vivo 19, 989-995 (2005)

25. Liu J, Yeo HC, Overvik-Douki E, Hagen T, Doniger SJ, Chyu DW, Brooks GA, Ames BN: Chronically and acutely exercised rats: biomarkers of oxidative stress and endogenous antioxidants. J. Appl. Physiol. (1985) 89, 21-28 (2000)

26. Lowry OH, Rosebrough NJ, Farr AL, Randall RJ: Protein measurement with the Folin phenol reagent. J. Biol. Chem. 193, 265-275 (1951)

27. Markowiak P, Slizewska K: Effects of probiotics, prebiotics, and synbiotics on human health. Nutrients 9, 1021 (2017)

28. Martarelli D, Verdenelli MC, Scuri S, Cocchioni M, Silvi S, Cecchini C, Pompei P: Effect of a probiotic intake on oxidant and antioxidant parameters in plasma of athletes during intense exercise training. Curr. Microbiol. 62, 1689-1696 (2011)

29. Matur E, Eraslan E (2012): The impact of probiotics on the gastrointestinal physiology. In: New Advances in the Basic and Clinical Gastroenterology, ed Brzozowski T, In Tech, Rijeka, pp. 51-74

30. Mikelsaar M, Zilmer M: Lactobacillus fermentum ME-3 - an antimicrobial and antioxidative probiotic. Microb. Ecol. Health Dis. 21, 1-27 (2009)

31. Myers R, Fredenburgh J, Grizzle W (2008): Carbohydrates. In: The Theory and Practice of Histological Techniques, eds Bancroft JD, Gamble M, Elsevier, Philadelphia, pp. 161-186

32. Ohkawa H, Ohishi N, Yagi K: Assay for lipid peroxides in animal tissues by thiobarbituric acid reaction. Anal. Biochem. 95, 351-358 (1979)

33. Olnood CG, Beski SSM, Iji PA, Choct M: Delivery routes for probiotics: effects on broiler performance, intestinal morphology and gut microflora. Anim. Nutr. 1, 192-202 (2015)

34. Pyne DB, West NP, Cox AJ, Cripps AW: Probiotics supplementation for athletes - clinical and physiological effects. Eur. J. Sport Sci. 15, 63-72 (2015)

35. Radak Z, Chung HY, Goto S: Systemic adaptation to oxidative challenge induced by regular exercise. Free Radic. Biol. Med. 44, 153-159 (2008)

36. Radak Z, Taylor AW, Ohno H, Goto S: Adaptation to exercise-induced oxidative stress: from muscle to brain. Exerc. Immunol. Rev. 7, 90-107 (2001)

37. Ravi Kiran T, Subramanyam MV, Prathima S, Asha Devi S: Blood lipid profile and myocardial superoxide dismutase in swim-trained young and middle-aged rats: comparison between left and right ventricular adaptations to oxidative stress. J. Comp. Physiol. B 176, 749-762 (2006)

38. Rosa EF, Freymuller E, Ihara SS, Aboulafia J, Nouailhetas VL: Damaging effects of intense repetitive treadmill running on murine intestinal musculature. J. Appl. Physiol. (1985) 104, 1410-1417 (2008) 
39. Salinas I, Meseguer J, Esteban MA: Antiproliferative effects and apoptosis induction by probiotic cytoplasmic extracts in fish cell lines. Vet. Microbiol. 126, 287-294 (2008)

40. Sanchez E, Nieto JC, Boullosa A, Vidal S, Sancho FJ, Rossi G, Sancho-Bru P, Oms R, Mirelis B, Juarez C, Guarner C, Soriano G: VSL\#3 probiotic treatment decreases bacterial translocation in rats with carbon tetrachloride-induced cirrhosis. Liver Int. 35, 735-745 (2015)

41. Santos RV, Caperuto EC, Costa Rosa LF: Effects of acute exhaustive physical exercise upon glutamine metabolism of lymphocytes from trained rats. Life Sci. 80, 573-578 (2007)

42. Souza-Rabbo MP, Araujo A, Sr., Fernandes TR, Oliveira AR, Bello-Klein A, Kaur K, Singal PK: Influence of exercise training frequency on cardiac and hepatic oxidative stress in rats. Exp. Clin. Cardiol. 8, 201-205 (2003)

43. Sun Y, Oberley LW, Li Y: A simple method for clinical assay of superoxide dismutase. Clin. Chem. 34, 497-500 (1988)

44. Unsal H, Unsal C, Uner AG, Yildirim EK, Ekici M, Balkaya M, Belge F: The effects of swimming exercise and probiotic VSL\#3 on zonulin and some inflammatory and oxidative parameters in rats. Kafkas Universitesi Veteriner Fakultesi Dergisi 23, 101-107 (2017)

45. West NP, Horn PL, Pyne DB, Gebski VJ, Lahtinen SJ, Fricker PA, Cripps AW: Probiotic supplementation for respiratory and gastrointestinal illness symptoms in healthy physically active individuals. Clin. Nutr. 33, 581-587 (2014)

46. West NP, Pyne DB, Cripps AW, Hopkins WG, Eskesen DC, Jairath A, Christophersen CT, Conlon MA, Fricker PA: Lactobacillus fermentum $\left(\mathrm{PCC}^{\mathbb{R}}\right)$ supplementation and gastrointestinal and respiratory-tract illness symptoms: a randomised control trial in athletes. Nutr. J. 10, 30 (2011)

47. Yang H, Liu A, Zhang M, Ibrahim SA, Pang Z, Leng X, Ren F: Oral administration of live Bifidobacterium substrains isolated from centenarians enhances intestinal function in mice. Curr. Microbiol. 59, 439-445 (2009)

48. Yason CV, Summers BA, Schat KA: Pathogenesis of rotavirus infection in various age groups of chickens and turkeys: pathology. Am. J. Vet. Res. 48, 927-938 (1987) 